\section{Look back with (some) anger, and a lot of pleasure}

\author{
Andrew Bush, ${ }^{1}$ lan Pavord ${ }^{2}$
}

This is the last issue put together by the editorial team that has been privileged to look after Thorax for the past five years. We have run out of Adrian Mole book titles, and we have left the seventh age of man for the incoming team to describe us. (For the literary challenged, "Last scene of all, That ends this strange eventful history, Is second childishness and mere oblivion; Sans teeth, sans eyes, sans taste, sans everything"-including the Fowler Cup!) It is time to move on and write our last editorial, in which we want to thank a huge number of people, look back at what we think went well and what did not, and, finally, to pay off some old scores!

First the thanks-we have had a great five years on a personal level, and this as well as any success that may have been achieved is down solely to the efforts of many people. Our deputy editors, Clare Lloyd and Paul Cullinan, have been towers of strength and support, and ensured that our weekly Hanging Committee has always been focused, feisty, and above all, fun. The associate editors have worked tirelessly to bring down decision times to about a third of what they were and guided us with really helpful summaries of the manuscripts. Many hundreds of reviewers have given long hours of valuable and valued time to give us their wisdom and expertise, for zero financial reward and no university or National Health Service recognition; to you all, many thanks, and to all the above, we hope your spouses have not cited us in divorce proceedings. Behind the scenes we have been helped so much by the Thorax staff. Our editorial assistants have always been prompt, efficient, and above all, patient; and the production team have accommodated our last-minute requests with unfailing helpfulness and good humour. A particular thanks to Claire Weinberg at BMJ Publishing-

\footnotetext{
${ }^{1}$ Department of Paediatric Respiratory Medicine and Paediatrics, Royal Brompton Hospital and Imperial College, London, UK; ${ }^{2}$ Respiratory Medicine Unit, Nuffield Department of Medicine, University of Oxford, Oxford, UK

Correspondence to Professor Andrew Bush, Department of Paediatric Respiratory Medicine and Paediatrics, Royal Brompton Hospital and Imperial College, Sydney Street, London SW3 6NP, UK; a.bush@imperial.ac.uk
}

perhaps the toll it took on her is shown by her first getting pregnant and then leaving the country for the West Coast of America during our tenure-were we really that bad, Claire? Finally, thanks to the authors of so many excellent papers, which it has been a privilege to review. We know we have not taken some that are close to your hearts, but this is inevitable given space constraints, and accepted or not, we have appreciated that all involved a lot of work and are of high quality; keep them coming for the new team. Thanks to the majority who accepted adverse decisions graciously, and to those who reverted to pins in Voodoo dolls, sorry, we are still alive and kicking and extend to you the traditional fingers of scorn (one from each of us).

We have been privileged to take a front seat at Thorax during what we suspect will be seen as the dawn of a golden era in respiratory medicine. Increasingly old paradigms are being abandoned and new thinking is coming to the fore. We even have some new effective treatments. Highlights that have played out in front of us, and which we have attempted to promote, include the following.

Airway disease: Given our backgrounds, perhaps unsurprisingly this is the first area in which we have tried to make an impact. We, aided by a terrific opinion article by Mark Fitzgerald, ${ }^{1}$ have waged a partially successful war on the flabby word 'exacerbations', which carries the implication that this is a transient inconvenience. ${ }^{1} 2$ 'Lung attacks' carry longterm implications; they are associated with a worse prognosis in cystic fibrosis (CF), for example. ${ }^{3}$ We were particularly happy to have a manuscript of a randomised controlled trial of two different physiotherapy techniques in CF used reduction in CF lung attacks as an endpoint, ${ }^{4}$ and, as an accompanying editorial pointed out, ${ }^{5}$ showed a positive result that would have been missed if spirometry had been chosen. The National Review of Asthma Deaths ${ }^{6}$ recommended a focused and speedy response after an asthma attack; depressing that this is still not done after many years of preventable deaths; this approach should surely be extended to all lung attacks in any disease.
We have also waged war on the nineteenth-century thinking that obfuscates by using umbrella terms rather than thinking clearly. ${ }^{7-10}$ There is nothing new under the sun-readers of Richard Asher will recognise the thoughts of this great man. So COPD means nothing more than premature airflow obstruction, and defining it by a fixed ratio irrespective of age or height is as sensible as defining short stature as a height of $120 \mathrm{~cm}$ at all ages. 'Asthma' is also increasingly recognised as a useless diagnosis unless qualified, a crusade we are going to inflict on readers elsewhere, and we enjoyed a final anti-ACOS rant. $^{10}$ Instead, we should abandon misleading names, engage our brains and use biomarkers to stratify airway disease, both in terms of risk and treatment, and a number of excellent articles have highlighted this, ${ }^{11-13}$ including extending this thinking to extrapulmonary comorbidities. $^{7}$

Hot off the breath: We were particularly pleased with this innovation. A special prize to Zarir Udwadia for the best opening line: "For 2 weeks in January, India coughed and the rest of the world paid attention". ${ }^{14}$ We were the first to discuss the Panther trial ${ }^{15}$ and the revolution in new treatments for idiopathic pulmonary fibrosis (IPF), ${ }^{16}$ and we did our best to fan the flames of a trans-Atlantic battle on outcome measures in IPF; ${ }^{17}$ we had a commentary on the lumacaftor-ivacaftor study within a month of publication; ${ }^{18}$ and many, many more. Credit to the production team-they held the presses rather than our jugulars, and really worked hard to ensure that we could get hot articles out quickly.

International papers: What do South African gold, Korean disinfectants and South American air pollution have in common? All were the subject of excellent papers in Thorax. ${ }^{19-23}$ We have tried to have a global focus, not just a British one, and have had great manuscripts about work carried out in particularly challenging circumstances including excellent TB manuscripts from developing (as well as developed) world settings. ${ }^{24-29}$ Sorry again to the unlucky developing world authors in particular-we had many great manuscripts that we could not take for space reasons, do not give up and do not send your best work elsewhere.

Angry old men: There have certainly been issues in the past five years; the tobacco industry and its evil spawn, the e-cigarette; and the cost of medications. The evil effects of children witnessing smoking in films formed the backbone of our tobacco-themed issue, ${ }^{30}$ which attained the dizzy heights of discussion by 
Loose Women; eat your heart out, Lancet Respiratory Medicine! The cosy-cosy relationship between ministers and the tobacco industry was highlighted in AIRWAVES, although sadly we doubt much ministerial slumber was lost. E-cigarettes remain controversial, as readers of our pro-con debate ${ }^{31} 32$ will appreciate; the clock has been turned well and truly back, with pictures of vapid eyecandy vaping-surely a great image to encourage smokers to quit? Increasingly the evidence is that, far from being a step down from smoking, they are a seductive step up. Bind them together, and legislate to treat tobacco and e-cigarettes as one, as Queensland, Australia have done; and since not even Dame Sally Davies knows what is in them, treat them as guilty until proven innocent, and don't hold your breath for the latter.

$\mathrm{CF}$ is a success story, in terms of moving from targeting downstream consequences of the disease to the fundamental molecular defect (other airway diseases, please note). However, the cost of these medications is formidable. First came ivacaftor (or I've a cost for), a highly effective medication for $5 \%$ of the CF population. ${ }^{33}$ Plenty of evidence, plenty of cost-probably around $£ 200 \mathrm{~K} /$ patient/ year, or for the UK, around an extra $£ 60$ million to the CF budget. Now comes the combination with lumacaftor, ${ }^{18}$ which has much more limited effects, BUT is applicable to $50 \%$ of the UK CF population. No one knows what the cost will be, but assume lumacaftor is half the price of ivacaftor, and you get an annual drug bill of $£ 1$ billion for the UK. Where will it end? Where is the business model to justify this price? The Helsinki Convention prevents Pharma from trialling expensive medications in the developing world and then withdrawing them as too expensive. Time to invoke this in the developed world as well? Let's have set criteria for calculating if a medication is value for money, such as the much-reviled National Institute for Health and Care Excellence use, and insist that no trials will be done unless this model is used to calculate costs. Radical? Yes, but not without precedent, and the alternative is likely handing Pharma the keys to the Bank of England under the completely comprehensible pressure of desperate patients.

Front covers: We have tried to liven these up-we moved from using a library that was too often wrong, to selecting figures from the current content. The Thorax team produced great covers for our ATS and ERS-themed issues- congratulations on artistic tours-de-force! We also had great photographs for TB and pneumonia-themed issues, and also the Drakenstein birth cohort study. ${ }^{34}$ We hope more talented photographers may be encouraged to offer their work to the journal.

And finally: Thanks again, and good luck to the incoming editors and their team, who will we are certain carry the Journal to new heights. If they are even half as well supported as we were, they will do well. We will miss editing Thorax, and one of us will especially miss seeing how much political incorrectitude and Pavord bating he could get into one page of AIRWAVES. We will particularly miss the sometimes heated debates at our weekly hanging committee. Charles De Gaulle famously remarked that "When I am right, I get angry. Churchill gets angry when he is wrong. We are angry at each other much of the time". The much bated and intrinsically dovish Pavord sometimes feels he has a similar relationship with his hawkish partner, who is unmasked as the snarling and psychopathic face of Thorax. Hilaire Belloc remarked once, "When I am dead, I hope it may be said: 'His sins were scarlet, but his books were read'". We are still alive (or were when we wrote this!), but we hope that although we certainly have sinned, at least you enjoyed reading at least some of what we thoroughly enjoyed writing (unless you are a Minister of Health or work in the tobacco industry)!

Provenance and peer review Commissioned; internally peer reviewed.

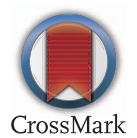

To cite Bush A, Pavord I. Thorax 2015;70:819-821.

Published Online First 15 July 2015

Thorax 2015;70:819-821.

doi:10.1136/thoraxjnl-2015-207508

\section{REFERENCES}

1 FitzGerald JM. Targeting lung attacks. Thorax 2011;66:365-6.

2 Bush A, Pavord I. Following Nero: fiddle while Rome burns, or is there a better way? Thorax 2011;66:367.

3 Sanders DB, Goss CH. Pulmonary exacerbations as indicators of progression of lung disease in young children with CF. Thorax 2013;68:608-9.

4 Mcllwaine MP, Alarie N, Davidson GF, et al. Long-term multicentre randomised controlled study of high frequency chest wall oscillation versus positive expiratory pressure mask in cystic fibrosis. Thorax 2013;68:746-51.

5 Main E. Airway clearance research in CF: the 'perfect storm' of strong preference and effortful participation in long-term, non-blinded studies. Thorax 2013;68:701-2.

6 Levy ML, Winter R. Asthma deaths: what now? Thorax 2015;70:209-10.

7 Agusti A, MacNee W. The COPD control panel: towards personalised medicine in COPD. Thorax 2013;68:687-90.

8 Agusti $A$. The path to personalised medicine in COPD. Thorax 2014;69:857-64.

9 Vanfleteren LE, Kocks JW, Stone IS, et al. Moving from the Oslerian paradigm to the post-genomic era: are asthma and COPD outdated terms? Thorax 2014:69:72-9.

10 Pavord I, Bush A. Two Lovely Black Eyes; Oh, what a surprise! Thorax 2015;70:609-10.

11 Hanania NA, Noonan M, Corren J, et al. Lebrikizumab in moderate-to-severe asthma: pooled data from two randomised placebo-controlled studies. Thorax 2015;70:748-56.

12 Wagener AH, de Nijs SB, Lutter R, et al. External validation of blood eosinophils, FE(NO) and serum periostin as surrogates for sputum eosinophils in asthma. Thorax 2015;70:115-20.

13 Arron JR, Izuhara K. Asthma biomarkers: what constitutes a 'gold standard'? Thorax 2015;70: 105-7.

14 Udwadia ZF. MDR, XDR, TDR tuberculosis: ominous progression. Thorax 2012;67:286-8.

15 McGrath EE, Millar AB. Hot off the breath: triple therapy for idiopathic pulmonary fibrosis-hear the PANTHER roar. Thorax 2012;67:97-8.

16 Ryerson CJ, Collard HR. Hot off the breath: a big step forward for idiopathic pulmonary fibrosis. Thorax 2014;69:791-2.

17 Wells AU, Behr J, Costabel U, et al. Hot of the breath: mortality as a primary end-point in IPF treatment trials: the best is the enemy of the good. Thorax 2012;67:938-40.

18 Jones AM, Barry PJ. Lumacaftor/ivacaftor for patients homozygous for Phe508del-CFTR: should we curb our enthusiasm? Thorax 2015;70:615-6.

19 Ross J, Ehrlich RI, Hnizdo E, et al. Excess lung function decline in gold miners following pulmonary tuberculosis. Thorax 2010;65:1010-5.

20 Hong SB, Kim HJ, Huh JW, et al. A cluster of lung injury associated with home humidifier use: clinical, radiological and pathological description of a new syndrome. Thorax 2014;69:694-702.

21 Kim HJ, Lee MS, Hong SB, et al. A cluster of lung injury cases associated with home humidifier use: an epidemiological investigation. Thorax 2014;69: 703-8.

22 Pickering CA. Humidifiers: the use of biocides and lung disease. Thorax 2014;69:692-3.

23 Forno E, Gogna M, Cepeda A, et al. Asthma in Latin America. Thorax 2015;70:898-905.

24 Ling DI, Nicol MP, Pai M, et al. Incremental value of T-SPOT.TB for diagnosis of active pulmonary tuberculosis in children in a high-burden setting: a multivariable analysis. Thorax 2013;68:860-6.

25 Theron G, Peter J, Meldau R, et al. Accuracy and impact of Xpert MTB/RIF for the diagnosis of smear-negative or sputum-scarce tuberculosis using bronchoalveolar lavage fluid. Thorax 2013;68:1043-51.

26 Michelsen SW, Soborg B, Koch A, et al. The effectiveness of $B C G$ vaccination in preventing Mycobacterium tuberculosis infection and disease in Greenland. Thorax 2014;69:851-6.

27 Saavedra-Campos M, Welfare W, Cleary P, et al. Identifying areas and risk groups with localised Mycobacterium tuberculosis transmission in northern England from 2010 to 2012: spatiotemporal analysis incorporating highly discriminatory genotyping data. Thorax. Published Online First: 28 Apr 2015. doi:10.1136/thoraxjnl-2014-206416 


\section{Editorial}

28 Haldar $\mathrm{P}$, Thuraisingam $\mathrm{H}$, Patel $\mathrm{H}$, et al. Single-step QuantiFERON screening of adult contacts: a prospective cohort study of tuberculosis risk. Thorax 2013;68:240-6.

29 Panchal RK, Browne I, Monk P, et al. The effectiveness of primary care based risk stratification for targeted latent tuberculosis infection screening in recent immigrants to the UK: a retrospective cohort study. Thorax 2014;69:354-62.
30 Waylen AE, Leary SD, Ness AR, et al. Cross-sectional association between smoking depictions in films and adolescent tobacco use nested in a British cohort study. Thorax 2011:66:856-61.

31 Britton J. Electronic cigarettes: pro. Thorax 2015;70:309-10.

32 Furber A. Electronic cigarettes: reasons to be cautious. Thorax 2015;70:307-8.
33 Bush A, Simmonds NJ. Hot off the breath: 'I've a cost for'-the 64 million dollar question. Thorax 2012;67:382-4

34 Zar HJ, Barnett W, Myer L, et al. Investigating the early-life determinants of illness in Africa: the Drakenstein Child Health Study. Thorax 2015;70:592-4. 